\title{
Manyetik Kaçak Akı İşaret Gürültüsü İçin Dalgacık Dönüşümü ve Tekrarlı Gauss Filtreleme Yöntemlerinin İncelenmesi
}

\author{
Investigation on Wavelet Transform and Iterative Gaussian Filtering Methods for Denoising \\ Signal of Magnetic Flux Leakage
}

\author{
Okan KARA ${ }^{1} \mathbb{D}$, Hasan Hüseyin ÇELİK ${ }^{2}$ \\ ${ }^{1}$ Milli Savunma Üniversitesi, Deniz Astsubay Meslek Yüksek Okulu, Elektronik ve Otomasyon Bölümü, 77720, \\ Yalova, Türkiye \\ ${ }^{2}$ Marmara Üniversitesi, Elektrik Elektronik Mühendisliği Bölümü, 34722, İstanbul, Türkiye
}

$\ddot{O}_{z}$

Manyetik kaçak akı (MKA) yöntemi, ferromanyetik özellikteki materyallerde oluşan çatlak, delik, korozyon gibi kusurları algılama amaçlı kullanılan tahribatsız test yöntemlerinden biridir. MKA sensörlerinden alınan işaretler test edilen materyal yapısında oluşan kusurları tanımlamakla birlikte gürültü bileşenlerini de içermektedir. Gürültü miktarı ve niteliği ise test sistemi ve materyal yapısına göre farklılıklar göstermektedir. Uygun olmayan bir filtreleme işlemi sonucunda, kusurları temsil eden işaretler, gürültü içerisinde kaybolmakta veya bozularak anlamını kaybetmektedir. Bu çalışmada MKA yöntemi ile alınan işaretler üzerinde dalgacık dönüşümü ve tekrarlı Gauss filtreleme yöntemlerinin etkinliği incelenmektedir. MKA işaretlerini üretmek amacıyla, ANSYS Maxwell benzetim ortamında manyetik test sistemi tasarlanmıştır. Test materyali olarak, üzerinde farklı büyüklükte 3 yapay kusur bulunan bir çelik plaka kullanılmıştır. Manyetik sistemden alınan işaretler üzerinde, ayrık dalgacık dönüşümü ve tekrarlı Gauss fitreleri uygulanmıştır. Filtrelenen işaretler üzerinde oluşan işaret bozulmaları ve simetri bozukluğu ele alınarak incelenmiştir. Deney sonuçlarına göre, MKA işaretleri üzerinde, tekrarlı Gauss filtresinin dalgacık dönüşümü yöntemlerinden daha başarılı sonuçlar ürettiği görülmektedir.

Anahtar Kelimeler: Manyetik Kaçak Akı, Kusur Tespiti, Gürültü Filtreleme, Dalgacık Dönüşümü, Tekrarlı Gauss filtre.

\begin{abstract}
Magnetic flux leakage (MFL) method is one of the non-destructive testing methods used to detect defects such as cracks, holes, and corrosion within ferromagnetic materials. Signals produced by MFL sensors, identify the defects occurred in structure of tested material also include noise components. The amount and property of the noise varies according to the test system and material structure. As a result of improper filtering, signals representing defects are lost in noise or distorted and become meaningless. In this study, the effectiveness of wavelet transform and iterative Gauss filtering methods on the signals obtained by applying MFL method was examined. In order to generate MFL signals, magnetic test system were designed in ANSYS Maxwell simulation environment. As a test material, a steel plate with 3 different size defects was used. Discrete wavelet transform methods and iterative Gauss filter were applied on the signals produced by the magnetic system. Signal distortions and symmetry disturbances which occured on the filtered signals were examined. According to experimental results, it is seen that iterative Gaussian filter produces more successful results than wavelet transform methods on MFL signals.
\end{abstract}

Keywords: Magnetic Flux Leakage, Defect Detection, Denoising, Wavelet transformation, Iterative Gaussian filter.

\section{GİRIS}

Teknolojik öneme sahip endüstriyel materyallerin yapılarında zamanla oluşabilen çatlak, aşınma, korozyon gibi bozulmalar önemli oranda can ve mal kayıplarına sebep olmaktadır. Üretim kusuru, ağır aşınma veya yıpranma kaynaklı olan bu bozulmaların yol açtığı kayıpları önlemek için, kritik öneme sahip materyallerin test edilmesinde periyodik olarak tahribatsız test yöntemlerine ait çeşitli teknikler kullanılmaktadır [1,2]. Tahribatsız test yöntemlerinden biri olan Manyetik Kaçak Akı (Magnetic Flux Leakage) yöntemi, ferromanyetik materyallerin yapısında oluşan çatlak, metal kaybı, korozyon gibi kusurları tespit eden etkin ve güvenilir bir yöntemdir $[3,4]$. Manyetik Kaçak Akı (MKA) yöntemi ile petrol ve gaz boruları, tank zeminleri, çelik halatlar, tren yolları ve gemi yapımında kullanılan ferromanyetik metal saclar gibi kritik yapı materyaller üzerinde periyodik hata testleri yapılmaktadır. Yöntemi önemli hale getiren, materyalin temassız bir şekilde muayenesinin sağlanması ve gözle görülemeyen iç kusurların tespit edilebilmesi gibi özelliklere sahip olmasıdır [5,6].

MKA yöntemi test işleminde, materyalin iç yapısına nüfuz edecek şekilde manyetik alan uygulanır ve yüzeyden yansıyan manyetik alan değişimleri ölçülür. Materyalin kusurlu bölgelerinde oluşan manyetik kaçak akılar, alınan işaretler üzerinde farklı genlikli değişimler üreterek kusurlu bölgelerin tespit edilmesini sağlar [7]. Bununla birlikte, 
materyal yüzeyi boyunca küçük değişimler gösteren manyetik geçirgenlik ve yüzey pürüzlülüğü gibi nedenlerle MKA işaretleri üzerinde gürültüler oluşmaktadır. Bu oluşan gürültüler, MKA işaretlerinin yorumlanması ve kusur niteliklerinin çıkartılması aşamasında olumsuz etkiler meydana getirir. Örneğin, küçük kusur işaretleri ile benzer seviyelerdeki gürültü işaretleri, küçük kusur sinyallerinin kaybolmasına veya işaretin anlamlı ayrıntılarının bozulmasına sebep olabilmektedir. Bu yüzden MKA işaretlerinin gürültü filtreleme işlemi önemli bir aşama olarak kabul edilir.

Fourier dönüşüm yöntemi, işaret işleme teknikleri içerisinde önemli bir yer tutmaktadır. İşaretlerin frekans düzlemindeki davranışları Fourier yöntemi ile zamandan bağımsız olarak gözlenebilir. Bu özellik filtre tasarım aşamasında önemli bir klavuz özelliği göstermektedir [8]. Dalgacık dönüşüm yöntemleri ise farklı dalgacık fonksiyonları kullanarak, işaretin frekans düzlemindeki değişiminin, zaman domeni ile ilişkilendirilmesini sağlar. $\mathrm{Bu}$ yüzden dalgacık dönüşüm yöntemleri, bir işaretin analizi ve filtrelenmesi gibi işlemlerde yaygın olarak kullanılmaktadır $[9,10]$.

Literatürde MKA sinyallerinin işlenmesi ve Dalgacık dönüşüm yöntemleri ile ilgili birçok çalışma bulunmaktadır. $\mathrm{Bu}$ çalışmalardan birinde [11] literatürde tanımlı gelen-yansıyan-iletilen güç bileşenlerinin, geleneksel Fourier dönüşümüne alternatif olarak dalgacık paket dönüşümü kullanılarak hesaplanması önerilmiştir. Çalışmada sonuç olarak; önerilen hesaplama tekniğinin etkinliği ve doğruluğu, gerçekleştirilen uygulamalarla gösterilmiştir. Dalgacık dönüşüm yöntemleri ile ilgili gerçekleştirilen bir diğer çalışmada [12], wavelet analiz tekniği ve uygulama alanları hakkında detaylı bir bilgi verilmiştir. W. Han ve Que P. gerçekleştirdikleri çalışmada [13] MKA sinyali gürültüsünü temizlemek için geliştirilmiş dalgacık dönüşümü tabanlı adaptif FIR filtresi algoritması tasarlamışlardır. Gerçekleştirilen bu algortima sonucu MKA sinyalinde bulunan kusur sinyal bölgelerinin tespit edilebilirliği yüksek derecede artırılmıştır.

$\mathrm{Bu}$ çalışmada, ANSYS Maxwell [14] benzetim ortamında MKA sistemi tasarlanarak, test materyaline ait MKA işaretleri elde edilmiştir. Alınan işaretler, aynı zamanda manyetik alan gürültüsü içeren bileşenleri de taşımaktadır. Matlab [15] yazılımı kullanılarak gerçekleştirilen gürültü ayıklama aşamasında ise, sayısal işaret üzerinde dalgacık dönüşümü ve tekrarlı Gauss filtresi yöntemleri uygulanarak, bunlara ilişkin sonuçlar, işaret gürültü oranı (SNR) ve işaret simetri bozulmaları temelinde ele alınarak incelenmiştir. Elde edilen sonuçlara göre tekrarlı Gauss filtresinin, MKA sistemi işaretlerinin karakterini daha fazla koruduğu ve incelenen dalgacık filtreleme yöntemlerine göre daha az işaret bozulmasına yol açtığı görülmüştür.

\section{MATERYAL VE YÖNTEM}

\subsection{MKA Yöntemi}

MKA yöntemi ferromanyetik materyallerin yapılarında oluşabilecek kusurların tespit edilmesini sağlayan tahribatsız bir test yöntemidir. Bu yöntem ile test edilen materyal üzerinde oluşan yüzey /yüzey altı korozyon ve çatlak gibi kusurların tespiti sağlanmaktadır. Bu yöntemde ferromanyetik materyalin test bölgesine güçlü bir manyetik alan uygulanarak malzemenin manyetik doyuma ulaştırılması gerekir. Manyetik doyuma ulaştırılmayan materyal üzerinde gerçekleştirilen test sonuçları kararsız ve düşük hassasiyette elde edilmektedir. MKA sistemi materyal üzerinde tarama yönü boyunca ilerletilerek alan etkili sensör dizisi ile ölçümler gerçekleştirilir. Materyalin kusur bulunan bölgelerinden havaya doğru kaçak akılar oluşur. Oluşan bu kaçak akılar, alan etkili sensörler tarafından algilanarak işaretlere dönüştürülür. Elde edilen işaretlerin yerel maksimum genlikli bölümleri materyalin kusurlu bölgelerini temsil etmektedir. MKA sistemi karşılıklı iki ters yönlü mıknatıs, bu iki mıknatıs arası bağlantıyı sağlayan manyetik köprü ve algılayıcı olarak alan etkili sensör bileşenlerinden oluşmaktadır. Materyal test aşamasında kullanılan MKA sistemi ve kusur bölgesinde oluşan kaçak akılar Şekil 1'de görülmektedir. Bu çalışmada, gerekli MKA sistemi ANSYS Maxwell benzetim programı üzerinde tasarlanarak oluşturulmuştur.

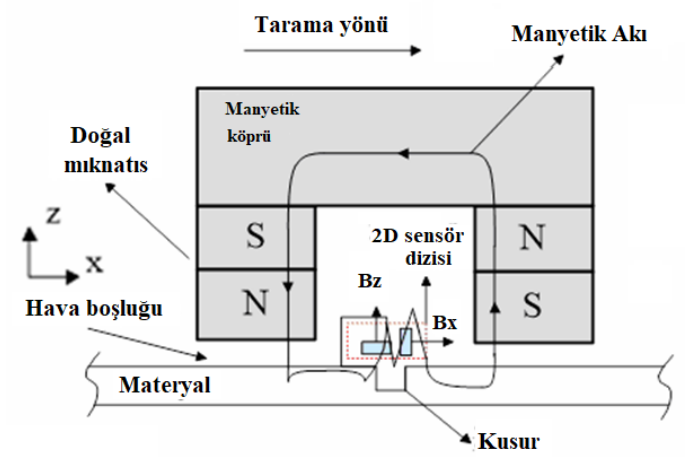

Şekil 1. Üzerinde kusur bulunan materyal için MKA sistemi davranışı

Bir metal plaka üzerinde 1,2 ve $3 \mathrm{~mm}$ çaplı yapay kusurlar oluşturularak deneyler gerçekleştirilmiştir. Şekil 2'de ANSYS Maxwell ortamında oluşturulan MKA sistem modeli görülmektedir.

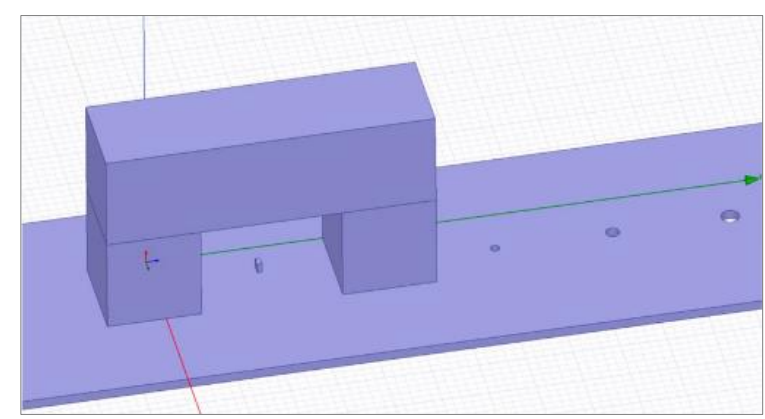

Şekil 1. ANSYS Maxwell MKA sistem modeli 


\subsection{Dalgacık Dönüşüm Yöntemleri}

Dalgacık dönüşüm yöntemleri Fourier yönteminden farklı olarak sinyalin frekans ve zaman düzlemindeki özelliklerinin birlikte değerlendirilebilmesini sağlar. Küçük dalgacık modelleri ile tanımlı ana fonksiyonlar ile bir işaretin bileşenlerine ayrılarak analiz edilmesi sağlanır. Dalgacık dönüşüm yöntemleri başta ses ve görüntü işaretleri olmak üzere birçok alanda yaygın olarak kullanılmaktadır [12].

\subsubsection{Sürekli dalgacık dönüşüm Yöntemi}

Sürekli Dalgacık Dönüşümü (SDD), dalgacıkların öteleme ve ölçek dönüşüm parametrelerinin zamana göre değişmesine olanak sağlayarak sinyalin frekanszaman uzaylarında analiz edilmesini sağlayan yöntemdir. Eşitlik (1) SDD formülünü tanımlar.

$X_{w}(a, b)=\frac{1}{|a|^{1 / 2}} \int_{-\infty}^{\infty} x(t) \bar{\psi}\left(\frac{t-b}{a}\right) d t$

Eşitlik (1)'de $a>0, b \in \mathfrak{R}$ ve $\bar{\psi}(t) \in L^{2}(R)$ şartını sağlamak kaydıyla, a ölçekleme ve $b$ dönüşüm veya öteleme parametrelerini ifade eder. $\bar{\psi}(t)$ sinyalinin SSD yöntemi ile gösterimini $X_{w}(a, b)$ olarak Eşitlik (1)'de gösterilmiştir. SSD yöntemi ile zamana göre frekansı değişen sinyallerin analizi gerçekleştirilerek sinyalin zaman-frekans diyagramı elde edilir [16]. SSD yöntemi ile dalgacık fonksiyonu sinyali x ekseni boyunca belirli bir ölçek parametresi $a$ değeri için konumu $b$ parametresine bağlı olacak şekilde tarar ve bu işlem her a değeri için tekrarlanır. Şekil 3 sinyal üzerinde dalgacık ilerlemesini ve sonuç matrisini göstermektedir.

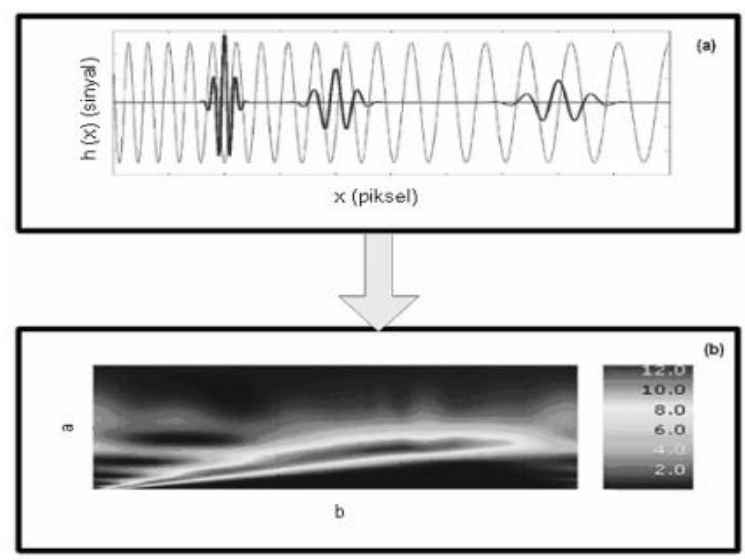

Şekil 3. (a) Üç farklı b değeri için, x ekseni boyunca sinyal üzerinde ilerleyen analiz dalgacığı; (b) bxa boyutlu SDD sonuç matrisi [16].

\subsubsection{Ayrık dalgacık dönüşüm yöntemleri}

Sürekli Dalgacık dönüşümünde kullanılan ölçekleme ve öteleme işlemleri, ikinin üsleri şeklinde oluşturularak Ayrık Dalgacık Dönüşümü (ADD) elde edilir ve sayısal işaretlere uygulanabilir [17]. ADD yönteminde kullanılan ayrık fonksiyon $f(n)$ ve ADD formülleri, Eşitlik (2) ve (3) ile tanımlanmıştır.

$$
\begin{aligned}
& c(a, b)=c(j, k)=\sum_{n=Z} f(n) y_{j, k}(n) \\
& y_{j, k}(n)=2^{-\frac{j}{2}} y\left(2^{-j} n-k\right)
\end{aligned}
$$

Coiflet, Daubechies ve Symlet, dalgacık dönüşüm yöntemleri sinyal işlemedeki etkinlikleri sebebi ile en yaygın kullanılan ADD yöntemleridir [18]. Şekil 4'de ayrık $x[n]$ işaretine ait 2 seviyeli ADD ayrışım ağacı ve bu ayrışımlar sonucu oluşan frekans bantları verilmiştir.

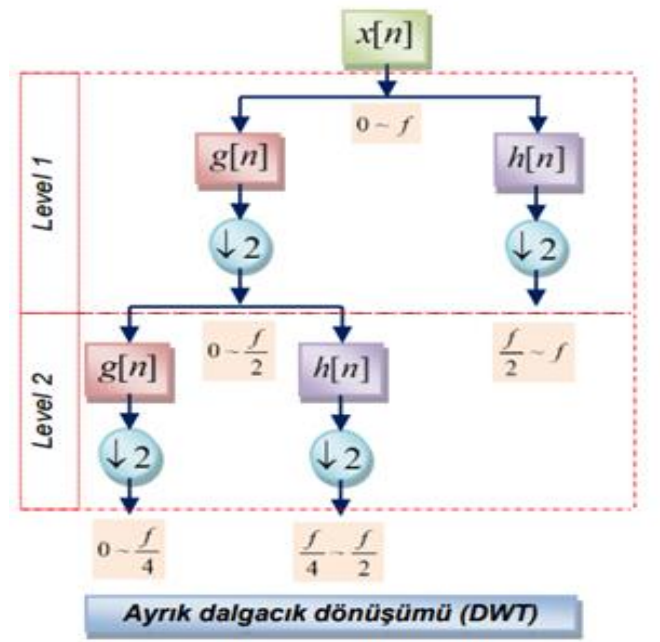

Şekil 4. ADD yöntemi ayrışım ağacı çizimi [11]

Haar, Daubechies, Coiflets, Symlets, dalgacık aileleri olmak üzere pratik uygulamalarda kullanılan birçok ayrık dalgacık ailesi bulunmaktadır. Gürültü filtrelemede yüksek derecede etkinliğinden dolayı [18], bu çalışmada Daubechies4 (db4), Daubechies5 (db5), Daubechies6 (db6), Symlet3 (sym3), Symlet4 (sym4), Symlet5 (sym5), Coiflet3 (coif3), Coiflet4 (coif4) ve Coiflet5 (coif5) dalgacık modelleri tercih edilmiştir. Bu çalışmada kullanılan dalgacık modelleri Şekil 5'de gösterilmiştir.

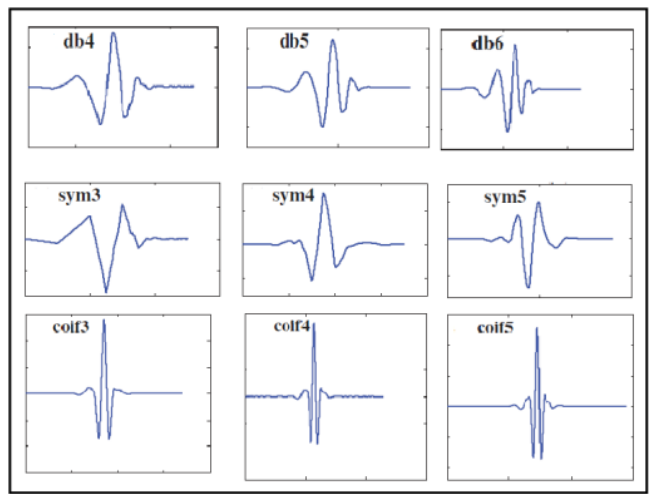

Şekil 5. Kullanılan Dalgacık Modelleri [18] 


\subsection{Tekrarlı gauss filtreleme yöntemi}

Tekrarlı Gauss filtresi, filtre uzunluğu 3 olan ve $c(-1): 0.2236, c(0): 0.5477$ ve $\quad c(1): 0.2236$

katsayıları ile uygulanan sayısal bir filtredir [19]. Bu katsayılar ile tekrarlı olarak gerçekleştirilen filtreleme işleminde, ilerleyen adımlarla ve toplam etki bakımından yüksek boyutlu Gauss filtresi ile yapılan filtreleme işlemine en iyi yakınsama sağlanmakla birlikte, yüksek boyutlu filtrenin oluşturduğu bozulma etkileri de en aza indirgenmektedir. $\mathrm{Bu}$ şekilde filtreleme işleminde temel problem olan eksik veya aşırı filtreleme etkileri giderilebilir. Tekrarlı filtreleme yönteminde, filtre boyunun belirlenmesi problemi tekrar sayısının uygun seçilmesine dönüşmektedir.

\section{BULGULAR VE TARTIŞMA}

Deneysel çalışmalarda ANSYS Maxwell ortamında hazırlanan ve yapısında 3 farklı kusur bulunan bir metal plaka oluşturulmuştur. Metal plaka parametrik olarak manyetik tarama işleminden geçirilerek MKA işaretleri elde edilmiştir. $\mathrm{Bu}$ aşamadaki tarama işlemlerinde, referans işareti üretmek amacıyla öncelikle yüksek çözünürlüklü ve düşük gürültüye sahip tarama örnek işaretleri elde edilmiştir. Daha sonra, sistem çözünürlügü düşürülerek daha yüksek gürültülü işaret örnekleri alınmıştır. Bu şekilde doğal manyetik ortam gürültüsü doğrultusunda yüksek gürültü oranına sahip örnek işaretlerin elde edilmesi amaçlanmıştır. Bu yaklaşım, yapay gürültü ekme şeklinde gerçekleştirilen test yöntemlerine bir alternatif olarak belirlenmiştir. Çünkü istatistiksel değişkenler ile modüle edilen yapay gürültü ekme işlemlerinde, alan ve uygulamaya özgü doğal gürültü karakteri elde edilememektedir. $\mathrm{Bu}$ çalışmada düşük gürültülü işaret referans işaret olarak kabul edilmiş ve filtrelerin değerlendirilmesi bu referans işaret üzerinden göreceli olarak gerçekleştirilmiştir.

Filtreleme işlemlerinde genel olarak, filtrelenen işaret üzerinde kaçınılmaz bozulmalar meydana gelmektedir. $\mathrm{Bu}$ bozulmaların en aza indirgenmesi, seçilen filtre türleri ve bunlara ilişkin uygun parametrelerin seçimine bağlıdır. Bu bağlamda filtreleme işleminin uygulamaya yönelik olarak seçilmesi kritik önem kazanmaktadır. Filtreleme işleminin performansını ölçmek amacıyla, sinyal gürültü oranı (SNR) değeri sıklıkla referans alınmaktadır. SNR değeri, işaretin tamamı üzerinden hesaplanan bir göstergedir. Ancak MKA işaretlerinde, işaretin tamamından daha çok kusur bölgeleri ön plana çıkmaktadır. Çünkü fiziksel kusuru niteleyen bilgiler, bu işaret bölgelerinden elde edilir. Yerel tepe noktaları kusur derinliğini, tepe noktasının sağ ve sol taraflarındaki ilk minimum noktalar arasındaki mesafe ise kusur çapını belirlemekte kullanılır. Filtreleme sonucu bu bölgelerde oluşan ve özellikle işaretin genlik ve genişlik değerlerinde oluşan bozulmalar, kusurların niteliği hakkında hatalı verilerin çıkartılmasına neden olacaktır.
$\mathrm{Bu}$ çalışmada MKA işaretleri üzerindeki filtreleme işlemlerinin başarısı, sinyal gürültü oranı yerine, kusur bölgelerindeki bozulmalar ve bu bozulmayı en iyi temsil eden simetri kayması üzerinden incelenmiştir. Değerlendirmelerde mutlak simetri değerleri yerine, referans işaretin sahip olduğu simetri değerleri referans alınmıştır. $\mathrm{Bu}$ çalışmadaki şekil ve tablolarda s: dalgacık seviyesi ve n: tekrar katsayısı parametrelerini ifade etmektedir.

Şekil 6 (a) ve (b)'de kusurlu metal plaka için sistemden alınan düşük ve yüksek gürültülü tarama işaretleri görülmektedir. Şekil 6 (a) ve (b)'de yer alan yüksek genlikli tepe bölgeleri dışındaki alanlarda yer alan gürültüler ise yüzeye ait manyetik akı gürültüsünü yansıtır. Deneysel çalışmalar, yüksek gürültülü işaretler üzerinde farklı filtre yöntemlerinin uygulanması ve düşük gürültülü referans işaret ile kıyaslanması şeklinde yürütülmüştür. Kıyaslama işlemleri sadece kusur bölgeleri için gerçekleştirilmiş ve bu bölgelerdeki simetri bozunumu oranları incelenmiştir. Şekil 7 (a) ve (b)'de kusur1 ve kusur2 için simetri bozulmasına ilişkin işaretler görülmektedir.

Simetri bozunumu katsayısı, her bir kusur işaretinin maksimum genlik noktasına göre sağ ve sol yarısındaki alanların birbirine oranı şeklinde hesaplanmıştır. Daha sonra 3 farklı kusura ait toplam hata ve referans işarete ait toplam hata değerleri ile kıyaslanarak hata miktarları elde edilmiştir.

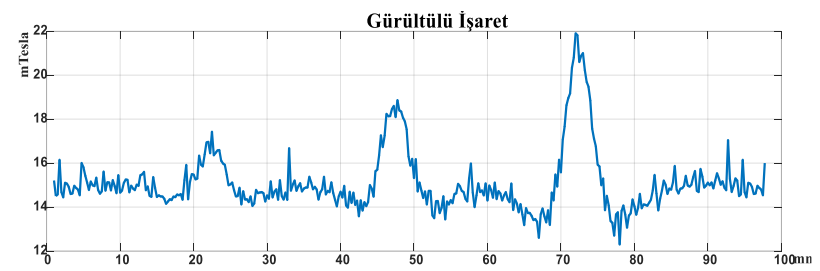

Şekil 6 (a). Gürültülü işaret

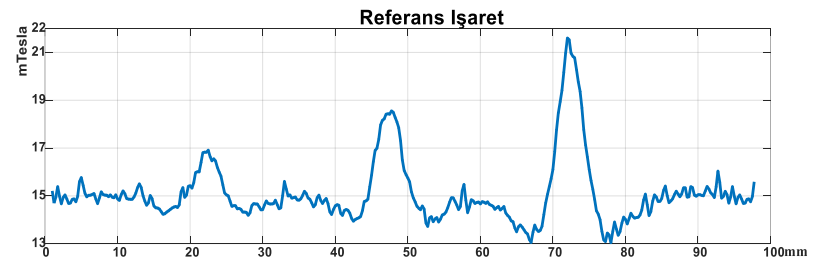

Şekil 6 (b). Yüksek çözünürlüklü referans işaret 


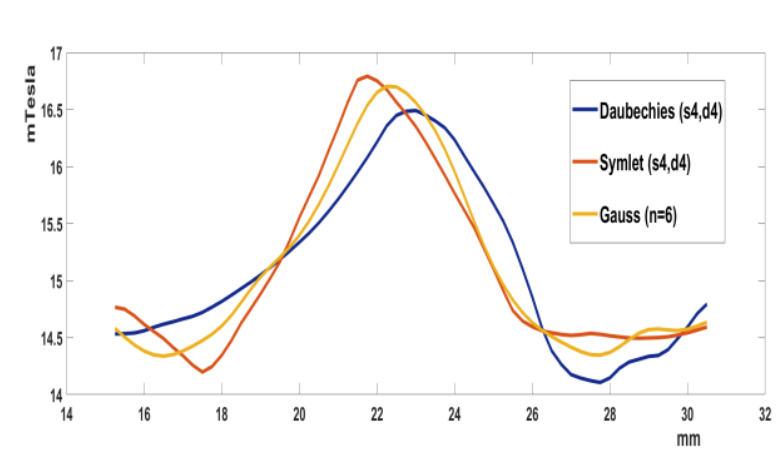

Şekil 7 (a). Kusur 1 için filtreleme sonucu simetrisi bozulmuş örnek işaretler

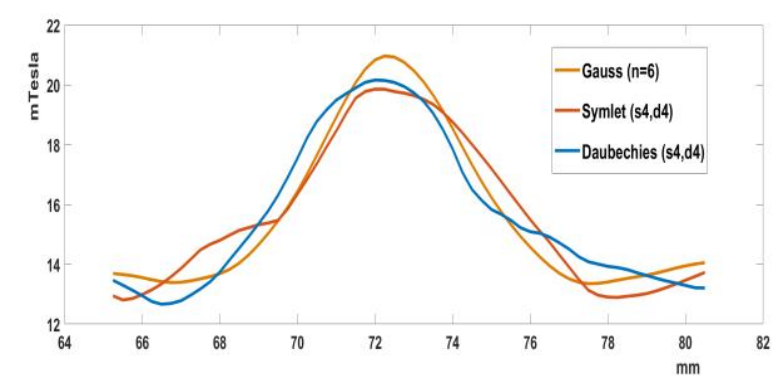

Şekil 7 (b). Kusur 2 için filtreleme sonucu simetrisi bozulmuş örnek işaretler

Filtreleme aşamasında MKA işareti üzerinde, db4, db5, db6, sym3, sym4, sym5, coif3, coif4 ve coif5 dalgacik yöntemleri ve bunlara ait farklı seviyeler uygulanmıştır. Daha sonra aynı işaret, tekrarlı Gauss filtresi ile 12 tekrar adımına kadar ayrı ayrı filtrelenmiştir. Tüm filtreleme işlemleri sonunda her bir filtreye ait SNR değerleri hesaplanmıştır. Dalgacık filtreleme yöntemleri ve Gauss filtresi arasında sağlıklı bir kıyaslama yapılabilmesi için, Gauss filtresinin tekrar sayısının uygun olarak belirlenmesi gereklidir. $\mathrm{Bu}$ amaçla dalgacık yöntemlerinden elde edilen SNR değerlerine en yakın sonuçları üreten Gauss filtresi adımları kıyaslama amaçlı olarak seçilmiştir. Seçilen filtre, diğer dalgacık modellerinden elde edilen en iyi sonuçlar ile kıyaslanmıştır. Tablo 1 'de gürültülü işaret, az gürültülü referans işareti ile gürültülü işaret üzerine uygulanan filtreleme işlemlerine ait SNR ve simetri katsayıları ile tanımlanan sonuçlar görülmektedir. Tablo 2' de ise elde edilen sonuçlardan derlenen hata miktarları yer almaktadır.

Tablo1. Filtreleme sonucu SNR ve simetri katsayıları

\begin{tabular}{|l|c|c|c|c|}
\hline $\begin{array}{l}\text { Filtre ve } \\
\text { Isşaret } \\
\text { Türleri }\end{array}$ & \multirow{2}{*}{$\begin{array}{l}\text { SNR } \\
\text { (Tüm } \\
\text { işaret) }\end{array}$} & \multicolumn{3}{|c|}{$\begin{array}{l}\text { Yerel Kusur işareti } \\
\text { Simetri Katsayıları }\end{array}$} \\
\cline { 3 - 5 } $\begin{array}{c}\text { Gürültülüu } \\
\text { işaret }\end{array}$ & 18.09 & -- & -- & -- \\
\hline $\begin{array}{c}\text { Referans } \\
\text { işaret }\end{array}$ & 19.26 & 1.005 & 1.021 & 0.997 \\
\hline $\begin{array}{c}\text { Gauss } \\
\text { (n=10) }\end{array}$ & 20.1 & 1.004 & 1.016 & 0.997 \\
\hline $\begin{array}{c}\text { Gauss } \\
\text { (n=6) }\end{array}$ & 19.42 & 1.001 & 1.013 & 0.998 \\
\hline coif4 (s:2) & 19.22 & 1.017 & 1.012 & 1.006 \\
\hline
\end{tabular}

\begin{tabular}{|c|c|c|c|c|}
\hline coif3 (s:2) & 19.22 & 1.017 & 1.006 & 1.003 \\
\hline coif5 (s:3) & 19.39 & 1.112 & 1.025 & 1.005 \\
\hline coif4 (s:3) & 19.38 & 0.987 & 1.172 & 0.998 \\
\hline $\begin{array}{c}\mathrm{db} 4 \\
(\mathrm{~s}: 4)\end{array}$ & 21.52 & 0.994 & 1.246 & 1.04 \\
\hline $\begin{array}{c}\mathrm{db} 4 \\
(\mathrm{~s}: 3)\end{array}$ & 19.46 & 1.014 & 1.337 & 1.033 \\
\hline sym6 (s:3) & 19.4 & 1.09 & 0.898 & 1.151 \\
\hline $\begin{array}{c}\mathrm{db} 5 \\
(\mathrm{~s}: 3)\end{array}$ & 19.45 & 1.098 & 0.892 & 1.178 \\
\hline $\begin{array}{c}\mathrm{db} 6 \\
(\mathrm{~s}: 3)\end{array}$ & 19.41 & 0.891 & 1.163 & 0.844 \\
\hline sym3 (s:2) & 19.23 & 0.892 & 0.884 & 0.837 \\
\hline sym5 (s:3) & 19.46 & 0.817 & 1.006 & 0.725 \\
\hline sym4 (s:3) & 19.49 & 1.378 & 1.041 & 1.428 \\
\hline sym4 (s:4) & 22.87 & 1.13 & 1.729 & 0.699 \\
\hline
\end{tabular}

Tablo 2 incelendiğinde her bir kusur bölgesi için farklı dalgacık modellerinin göreceli üstünlükleri görülmektedir. Aynı değerlendirme tekrarlı Gauss filtresi için de geçerlidir. Bu farklılıklar, yerel kusur işaretlerinin yapısal özellikleri ve aynı zamanda gürültünün küçük genlikli işaretler üzerinde oluşturduğu bozulma oranlarından kaynaklanmaktadır. Ancak 3 kusur için toplam simetri hatası dikkate alındığında, tekrarlı Gauss filtresinin diğerlerinden daha düşük hata ürettiği görülmektedir. Şekil 8'de görülen analiz sonuçları, tekrarlı Gauss filtresinin bu tür uygulamalarda daha yüksek filtreleme kalitesi sağladığını göstermektedir. Ayrıca SNR oranlarının, simetri bozulmasını esas alan bir yaklaşım ile paralel sonuçlar sağlamadığı görülmektedir. Bunun nedeni SNR oranının tüm işaret için hesaplanması gerekliliği gösterilebilir. Kiyaslamada bölgesel SNR hesaplama alternatif bir yaklaşım gibi görünmesine rağmen, bu uygulama bölge tespiti filtreleme işlemi gerektirmektedir. Aksi halde gürültülü işaret üzerinde yerel maksimum ve minimum noktalar sağlıklı olarak tespit edilemeyecektir.

Tablo2. Referans işarete göre simetri hataları

\begin{tabular}{|l|l|l|l|l|l|}
\hline & SNR & $\begin{array}{l}\text { kusur1 } \\
\text { hata }\end{array}$ & $\begin{array}{l}\text { kusur2 } \\
\text { hata }\end{array}$ & $\begin{array}{l}\text { kusur3 } \\
\text { hata }\end{array}$ & $\begin{array}{l}\text { Toplam } \\
\text { hata }\end{array}$ \\
\hline $\begin{array}{l}\text { Gauss } \\
(n=10)\end{array}$ & 19.42 & 0.001 & 0.005 & 0 & 0.006 \\
\hline $\begin{array}{l}\text { Gauss } \\
(\mathrm{n}=6)\end{array}$ & 20.1 & 0.004 & 0.008 & 0.001 & 0.013 \\
\hline $\begin{array}{l}\text { coif4 } \\
(\mathrm{s}: 2)\end{array}$ & 19.22 & 0.012 & 0.009 & 0.009 & 0.03 \\
\hline $\begin{array}{l}\text { coif3 } \\
(\mathrm{s}: 2)\end{array}$ & 19.22 & 0.012 & 0.015 & 0.006 & 0.033 \\
\hline $\begin{array}{l}\text { coif5 } \\
(\mathrm{s}: 3)\end{array}$ & 19.41 & 0.107 & 0.004 & 0.008 & 0.119 \\
\hline $\begin{array}{l}\text { coif4 } \\
(\mathrm{s}: 3)\end{array}$ & 19.4 & 0.018 & 0.151 & 0.001 & 0.17 \\
\hline db4 (s:4) & 19.39 & 0.011 & 0.225 & 0.043 & 0.279 \\
\hline db4 (s:3) & 19.38 & 0.009 & 0.316 & 0.036 & 0.361 \\
\hline $\begin{array}{l}\text { sym6 } \\
(\mathrm{s}: 3)\end{array}$ & 19.45 & 0.085 & 0.123 & 0.154 & 0.362 \\
\hline db5 (s:3) & 21.52 & 0.093 & 0.129 & 0.181 & 0.403 \\
\hline
\end{tabular}




\begin{tabular}{|l|l|l|l|l|l|}
\hline db6 (s:3) & 19.23 & 0.114 & 0.142 & 0.153 & 0.409 \\
\hline $\begin{array}{l}\text { sym3 } \\
(\mathrm{s}: 2)\end{array}$ & 19.46 & 0.113 & 0.137 & 0.16 & 0.41 \\
\hline $\begin{array}{l}\text { sym5 } \\
(\mathrm{s}: 3)\end{array}$ & 19.46 & 0.188 & 0.015 & 0.272 & 0.475 \\
\hline $\begin{array}{l}\text { sym4 } \\
(\mathrm{s}: 3)\end{array}$ & 22.87 & 0.373 & 0.02 & 0.431 & 0.824 \\
\hline $\begin{array}{l}\text { sym4 } \\
(\mathrm{s}: 4)\end{array}$ & 19.49 & 0.125 & 0.708 & 0.298 & 1.131 \\
\hline
\end{tabular}

işaretinden hatalı sonuçların üretilmesine yol açmakta ve kullanılacak filtre seçimini daha önemli hale getirmektedir. Tekrarlı Gauss filtresi yöntemi ile bir yandan Gauss eğrisi tabanlı filtreleme etkisi sağlanırken diğer yandan ilerleyen filtre adımları ile oluşan bozulma etkilerinin izlenmesi sağlanabilmektedir. Tekrarlı Gauss filtresi yönteminin bu kabiliyeti, MKA ve benzeri yerel özelliklerin öne çıktığı uygulamalarda, filtre parametrelerinin optimizasyonunu sağlamakta önemli bir araç olarak kullanılabilir.

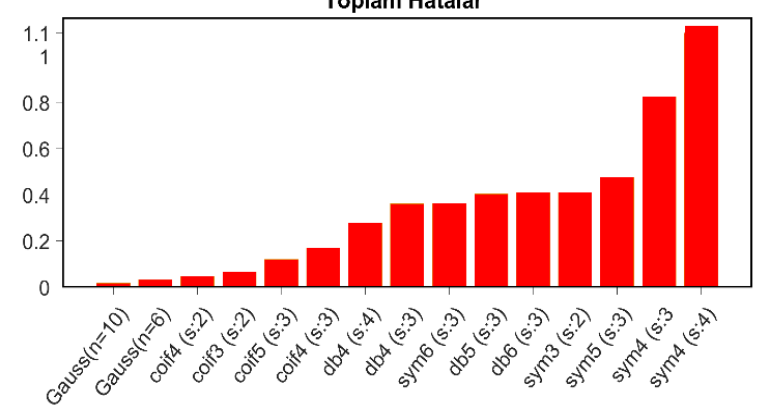

KAYNAKLAR

[1] LiYing, S., YiBo, L., LiBo, S. ve LingGe, L. (2012). Comparison of Magnetic Flux Leakage (MFL) and Acoustic Emission (AE) techniques in corrosion inspection for pressure pipelines", In Control Conference (CCC), Chinese, 5375-5378.

[2] Baskaran, R. ve Janawadkar, M.P. (2008). Defect localization by orthogonally projected multiple signal classification approach for magnetic flux leakage fields, $N D T \& E$ International, 41, 416- 419.

\section{SONUÇ}

$\mathrm{Bu}$ çalışmada, temassız metal muayene alanında kullanılan MKA işaretleri üzerinde, dalgacık filtreleme ve tekrarlı Gauss filtreleme yöntemleri karşılaştırmalı olarak incelenmiştir. Yöntemlerin başarısı, filtreleme sonucu kusur bölgelerinde oluşan simetri bozulmaları açısından değerlendirilmiştir. $\mathrm{Bu}$ amaçla ANSYS Maxwell benzetim ortamında, 3 farklı büyüklükteki delik kusurların algılanmasını sağlayan bir deney sistemi tasarlanmıștır. Sistemden az ve çok gürültülü olmak üzere iki tür işaret alınmıştır. Az gürültülü işaret filtreleme yeteneğini ölçmek amaciyla referans işaret olarak kullanılmıştır. Çok gürültülü MKA işaretleri üzerine, tekrarlı Gauss ve dalgacık filtreleme yöntemleri uygulanarak bu yöntemlerin filtreleme başarısı incelenmiştir. Filtreleme işlemlerinin başarısı, SNR değeri ile birlikte işaretin kusur bölgelerinde oluşan simetri bozunumu hesaplanarak değerlendirilmiştir. Çünkü kusur işaretinin doğal hali simetriklik özelliği taşımakta ve kusur bölgelerindeki noktasal kaymalar bu özelliği genellikle olumsuz yönde etkilemektedir. Bu yüzden tüm işaret için hesaplanan SNR değeri yerel bozulmaları tanımlamakta tek başına yetersiz kalabilmektedir.

Elde edilen sonuçlara göre tekrarlı Gauss filtresinin, kusur bölgesine ait işaret karakterini daha fazla koruduğu ve incelenen dalgacik filtreleme yöntemlerine göre daha az işaret bozulmasına yol açtığ görülmektedir. Özellikle işaretin küçük kusurlara ait bölümlerinin, filtreleme sonucu oluşan bozulmalardan daha fazla etkilendiği görülmektedir. Bu durumun sebebi, manyetik algılama sisteminde var olan gürülttünün, küçük kusurlar üzerinde daha yüksek oranda oluşmasıdır. Ayrıca, yerel maksimum ve minimum noktalarına örtüşen gürültü genliği de kusur işaretinin yapısını önemli ölçüde bozduğu deneysel çalışmalarda görülmüştür. Sözü edilen etkiler, MKA

[3] Coughlin, C. R., Clapham, L. ve Atherton, D. L. (2000). Effects of stress on MFL responses from elongated corrosion pits in pipeline steel, NDT \& E International, 33(3), 181-188.

[4] Ravan, M., Amineh, R. K., Koziel, S., Nikolova, N. K., ve Reilly, J. P. (2010). Sizing of 3-D arbitrary defects using magnetic flux leakage measurements, IEEE transactions on magnetics, 46(4), 1024-1033.

[5] Li, C., Li, Z., ve Jia, W. (2019). Theoretical study on the characteristics of self-magnetic flux leakage signals from pipeline defects. Insight - Non-Destructive Testing and Condition Monitoring, 61(9), 536-541.

[6] Xiao-meng L., Hong-sheng, D. ve Shi-wu, B. (2014). Research on the stress-magnetism effect of ferromagnetic materials based on three-dimensional magnetic flux leakage testing, NDT\&E International, 62, 50-54.

[7] Atzlesberger, J. ve Zagar, B. (2010). Magnetic flux leakage measurement setup for defect detection, Procedia Engineering, 5, 1401-1404.

[8] Nur, Y., Muzafir, I., Haziah, H., Mohd, R. A., Mohamad, N. K. H. R., Chai, C. Y. ve Nurul, N. A. (2016). Denoising Technique for Partial Discharge Signal: A Comparison Performance between Artificial Neural Network, Fast Fourier Transform and Discrete wavelet transform, IEEE International Conference on Power and Energy, 311-316.

[9] Daniel, J., Mohanagayathriand, R. ve Abudhahir, A. (2014). Characterization of Defects in Magnetic Flux Leakage (MFL) Images using Wavelet Transformand Neural Network, International Conference on 
Electronics and Communication Systems. 1-5.

[10]Kaya, M. ve Guldemir, H. (2007). Dalgacık Dönüşümü İle En Düşük Anlamlı Bit Filigran Ekleme Yöntemlerinin Kaynaştırılması, Doğu Anadolu Bölgesi Araştırmalart, 5 (4), 4-8.

[11] Vatansever, F., 2020, Güç bileşenlerinin dalgacık dönüşümü tabanlı Hesaplanması, Uludağ Üniversitesi Mühendislik Fakültesi Dergisi, 25 (2), 679-692.

[12] Öner, V. İ., Yeşilyurt, K. M., Yılmaz, Yılmaz, Ç, E., (2017), Wavelet analiz tekniği ve uygulama alanları, Ordu Üniv. Bil. Tek. Derg. 7(1), 42-56.

[13]Han, W., Que, P., 2006, A modified wavelet transform domain adaptive FIR filtering algorithm for removing the SPN in the MFL data, Measurement, 39, 621-627.

[14]ANSYS, (2021), ANSYS Maxwell, https://www.ANSYS.com/products/electroni cs/ANSYS-maxwell.

[15] Mathworks (2021), MATLAB, www.mathworks.com.

[16] Türkkan, L., (2015), Sürekli Dalgacık Dönüşümü İle Yüzey Ölçümü, Yüksek Lisans Tezi.

[17] Yang, Z., Dai, G., Zhao, H. ve Jiang, Y. (2009). Research of Magnetic Flux Leakage Signal Processing Based on Wavelet Denoising and EMD", 2nd International Congress on Image and Signal Processing, 14.

[18] Ou Z. ve Xueye W., (2019), De-noising of Magnetic Flux Leakage Signals Based on Wavelet Filtering Method, Research In Nondestructive Evaluation, 30 (5), 269-286, https://doi.org/10.1080/09349847.2018.1476 745.

[19] Ray, B., ve Ray, K. (1995). Corner Detection Using Iterative Gaussian Smoothing With Constans Window Size, Pattern Recognition, 28 (11), 1765-1781. 